\title{
A Critical Review of Child-Friendly Environments, Focusing on Children's Experiential Perspectives on the Physical World for Sustainability
}

\author{
Min Jee Nikki Han and Mi Jeong Kim *D \\ Department of Housing and Interior Design, Kyung Hee University, Seoul 02447, Korea; minjee83@hotmail.com \\ * Correspondence: mijeongkim@khu.ac.kr; Tel.: +82-2-961-9275
}

Received: 13 September 2018; Accepted: 9 October 2018; Published: 16 October 2018

check for updates

\begin{abstract}
The concept of child-friendliness has appeared in numerous research studies concerning sustainability and the wellbeing of children. For this critical review of child-friendly environments (CFEs), an evaluation framework of CFEs has been developed, consisting of four principal experiential categories: sociality, wellness, development, and independence of children. Despite considerable research on CFEs since the middle of the twentieth century, there have been few evaluations of CFEs focusing on children's experiences in relation to the physical environment. Through an exhaustive analysis of selected papers in this research, it was found that most papers have focused on the physical experiences of children, rarely mentioning the emotional experiences of children in relation to the physical environment. The environmental experiences of children are very critical for a balanced development in their emotional, physical, and intellectual comprehension. Therefore, research on CFEs should consider the balanced emotional, physical, and intellectual development of children. This research critically highlights the aspects of children's experiences to be addressed in CFEs research, exploring valuable insights into the environmental cognition of children and their development. A better understanding of children and an interpretative analysis of their experiences will lead to adequately balanced CFEs, creating sustainable environments.
\end{abstract}

Keywords: child-friendly environments; sustainable development; children's experience; physical activity; environmental consciousness; user experience; evaluation framework

\section{Introduction}

Researchers have explored child-friendly environments (CFEs) from various perspectives over the past decades. Many have recognised that CFEs can help provide sustainable environments appropriate to all age groups in several ways [1]. The realisation of CFEs has become an important issue among scholars since the mid-twentieth century, mostly in relation to the sociology of childhood and the perception of children's learning development as being inferior to that of adults [2]. In the twenty-first century, many researchers have become interested in children's quality of life and have begun to explore CFEs from the child's perspective, perceiving children as independent social participants. The reviews of CFEs and sustainable child development have been conducted by many researchers previously [3,4]. However, these papers considered limited criteria for CFEs, focusing mainly on the physical and intellectual value of child development. These criteria are independent mobility, safety, accessibility, connectivity, participation, play, and health. Independent mobility, affordances, participation, and safety were the major concerns of numerous studies in relation to the physical environment. These are the influential factors for shaping CFEs according to adult criteria. The current studies of CFEs are limited because they take an adult perspective. This research suggests a need for 
further exploration of the criteria of CFEs from the perspective of children, considering the balanced emotional, physical, and intellectual development of children.

Many studies on CFEs have focused on wellbeing [2,3,5-8] and sustainability $[3,4,9,10]$. These studies have introduced new frameworks, including an 'indicator of local environmental quality' [3] and 'a functional taxonomy of affordances scale' [11]. These new approaches to CFEs are a positive development. Nevertheless, there has been little research rigorously reviewing the main user of CFEs-children's user experiences of CFEs. Twenty-first century researchers have suggested various influential factors effective for the physical composition of CFEs, including independent mobility, affordances, neighbourhood interaction, social participation, and green spaces. This research has gathered all the influential factors suggested by the selected research and formed a CFEs indicator framework.

This research reviews CFEs, adopting an evaluation framework consisting of four principal experiential categories: sociality, wellness, development, and independence of children. This evaluation framework of CFEs has enabled a critical review of selected papers. A Harvey Ball has been used to analyse the CFEs value of each paper based on the children's experiential categories indicated in the evaluation framework. To create better environments for children, this research critically analyses and explores the current status of studies on CFEs, highlighting the value of children's experience in relation to the physical environment. A good environment for children is a place where they can move freely and interact with the environment through a variety of activities. A small town in Finland, Bullerby_literally meaning 'a noisy village' — is examined as a good CFE [11], offering children highly independent mobility and actualisation of affordances.

\section{Related Works}

\subsection{Children and Environments}

Many researchers in the urban and environmental field have focused on the topic of CFEs as the key to achieving sustainable environments. The configuration of CFEs is significant because "children and adults view the world differently" (p. 3, [12]) Most of the physical environments in our community are designed and built from an adult perspective, despite the fact that the most likely users are children. This research emphasises the need to create CFEs based purely on children's overall experiences of environments. How children greet and experience their environment is explored further to provide proper and adequate environments for them in the future. Children learn and improve themselves through environmental experiences and cognition. Unlike adults, children absorb large amounts of information and opportunities from the environment through active investigation, such as exploratory play and constructive craftwork. This critically affects their emotional, physical, and intellectual development [12], which means the environment is at the heart of children's overall life progression. Diversity of environments is critical to providing greater exploratory and creative potential and wider opportunities for play and socialisation [12].

The environmental experiences of children are critical for their emotional, physical, and intellectual development [12,13]. Research on CFEs should consider the balance of emotional, physical, and intellectual experiences of children. This research critically highlights the issues of children's experiences to be addressed in CFEs, exploring valuable insights into the environmental cognition of children and their development. Overall, the physical environment reflects and conditions the wellbeing of children and gives them clear messages about how they are valued within a community [3]. The healthy development of children is dependent on how well the environment and community are structured and designed to serve children [14]. The physical environment covers a wide spectrum [3] because it includes urban forms, shapes, and characteristics as well as buildings, roads, natural environments, and open spaces. From the perspective of children, fully polished and furnished environments are not always satisfactory. As Jansson et al. argued [15], unmanaged areas are useful for exploration, play possibilities, and a sense that the place belongs to the child. The more diverse the 
environment, especially outdoors, the greater the exploratory and creativity potential and the wider the play and social-scenario range [12].

Outdoor spaces including playgrounds, green spaces, and parklands offer a variety of activity options for children. For example, playgrounds offer general affordances for equipment play but also for chasing, hiding, ball games, and, more importantly, as meeting and hanging out places for children [15]. Green spaces offer a wider spectrum of experiences for children, such as walking on grass, running, picnics, sledging down hills, and sunbathing. Therefore, serving children with diverse outdoor spaces is important for balance of emotional, physical, and intellectual experiences. Providing appropriate indoor spaces such as schools and community centres is also critical for CFEs [8]. This directly affects children's experiences in learning, welfare, and sociality. Much research on the physical relationship between indoor and outdoor spaces concerns independent mobility and accessibility for children; however, there is a lack of exploring indoor spaces in conjunction with a variety of possible indoor activities.

Many researchers have investigated the significance of natural environments for CFEs, which also affect children's subjective wellbeing [2]. Natural spaces have been identified as children's favourite places [2]. However, the natural environment is not a unitary concept. The natural environment refers to diverse characteristics, such as pure nature, socially constructed nature, and culturally constructed nature. To enhance the engagement of children with natural environments in a safe and healthy way, the role of CFEs is very important.

\subsection{Sustainability and Child-Friendly Environments}

Sustainability is a principal value in the creation of CFEs. The lives, mobility, and everyday experiences of children are substantially affected by large-scale urban extensions and social and climate changes [1]. Research into multidisciplinary childhood studies related to the environment and spaces is internationally recognised as a significant concern. Many researchers have stated that CFEs have multiple values, contributing to sustainable development (SD) in various ways. Sustainability in CFE studies does not simply involve sustaining the original environment or the consumption of resources or reducing the dumping of waste [16]. The concept of sustainability in CFE studies focuses on the wellbeing and healthy development of children, especially their physical, social, emotional, and cognitive development [14]. A sustainable environment is critically relevant to children's SD. Children must be given the opportunity to develop in freedom and in a well-balanced society, which requires the satisfaction of basic needs and protection of the environment [4]. In our current society, SD is oriented to an adult perspective, while children's opportunities for and influence of SD is neglected. Children are more susceptible to their surrounding environments than adults, and this can have a great effect on their development.

CFEs and SD are inseparable concepts for achieving a sustainable environment that includes environmental equality for children. Current studies of CFEs in relation to SD are inadequate and lack practical tools for assessing and improving practices related to CFEs [3]. Sustainability in CFEs encompasses a variety of components including health, education, safety, economic status, participation, environmental aspects, and relationships. The combination of these components in a balanced form should be offered in an appropriate physical environmental setting for children. Approaching sustainability from children's perspectives for their sustainable development is also very important. However, as seen in the analysis of CFE studies in this research (shown in Table 1), most studies consider only one or two components of sustainability in CFEs. Many studies $[3,4,9,10]$ have focused on the context of neighbourhood setting, social infrastructure, and community planning as key issues for achieving sustainability in CFEs. Most studies of CFEs have focused on social context, community participation, sense of belonging, mobility, and connectivity. Affordance in relation to the safety of physical environments has been discussed by many studies of CFEs $[2,7,9,11,15,17,18]$. This research uses an evaluation framework consisting of four major categories-sociality, wellness, development, and independence-oriented by the experiences of children. This evaluation framework 
was established by gathering all the components considered in selected CFE papers. These components were then categorised into four major categories related to the balanced experiences of children connected to emotional, physical, and intellectual development.

Table 1. Contextual analysis of child-friendliness factors from each article, focusing on children's experiences of the physical world.

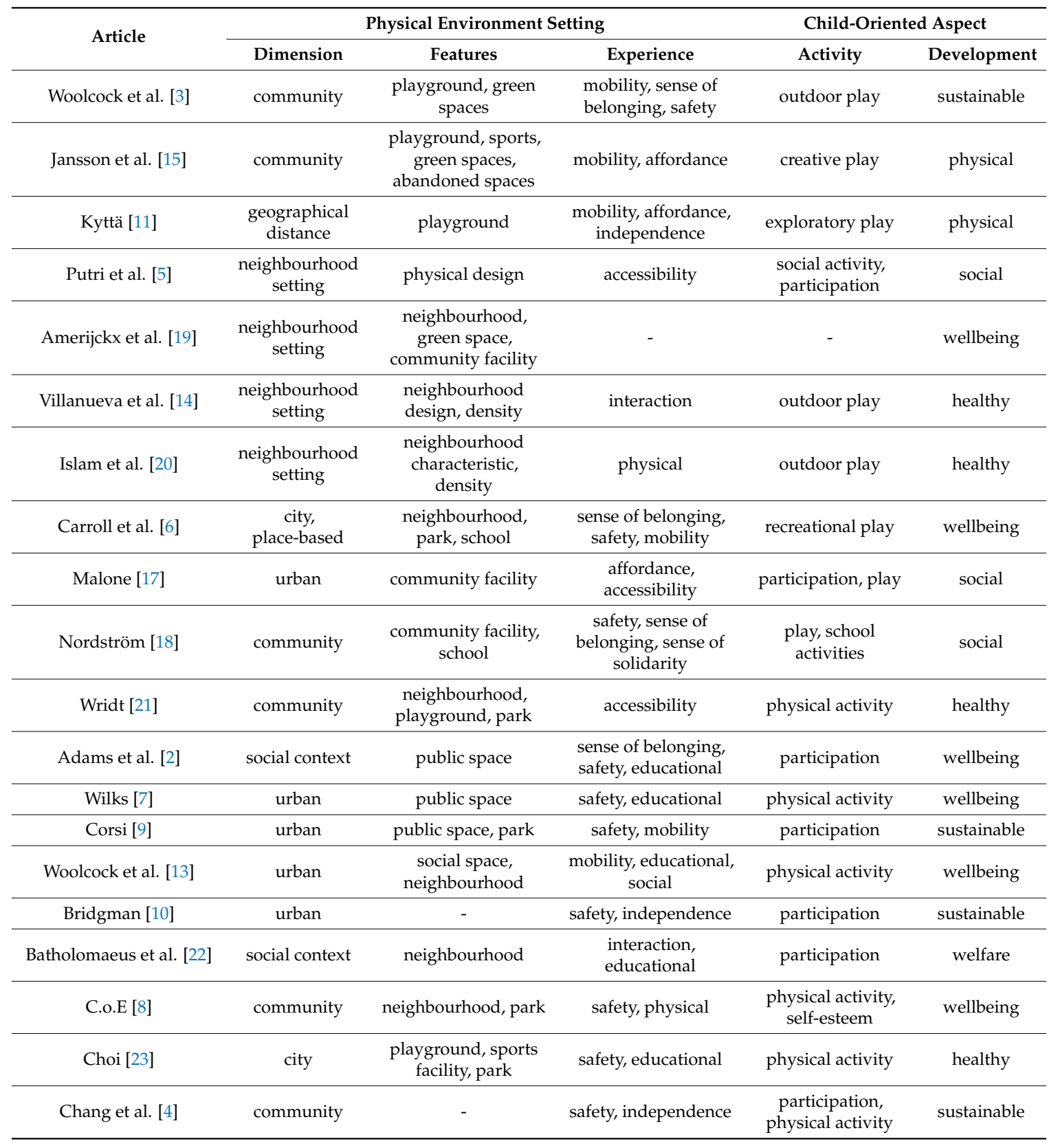

CFEs should aim to provide a sustainable environment for children that is not affected by ongoing urban and social changes. The CFEs should not be a temporary or 'trendy' urban environment. The physical environment should be structured based on the experiences of children and adults alike. CFEs promote environmental equality by providing multiple sustainable values. Children need the environment to serve their needs. The role of adults in achieving a sustainable environment through the development of CFEs should be explored in future studies of CFEs. 


\section{Methodology}

\subsection{Selection}

Woolcock et al. [3] reviewed leading academic articles related both to the child friendliness of communities and aspects of the physical environment, focusing mainly on articles from academic journals (for example, Journal of Environmental Psychology, Journal of Urban Design, and Children's Environments). Other sources, including books, reports, websites, and relevant newspaper articles, were also referenced in their review. Articles were collected for this review using a similar search method as Woolcock et al. To conduct a critical review of CFEs focused on children's experiences in the physical environment, keywords were specified and used for searching electronic databases and Google search engines. The keywords used included 'child-friendly environment', 'child-friendly city', 'child-friendly experience', 'children and physical environment', and 'children experience'. Unexpectedly, there were few papers directly including those keywords. Therefore, the keywords 'children and community', 'children wellbeing', and 'sustainable environment for children' were included and the databases were searched again. Fifty-five articles on CFEs were selected. Twenty-five of these articles were excluded because of inadequate content.

Each paper was read to determine the level of relevance based on set criteria; for example, articles dealing specifically with certain age groups or specific conditions, including obesity, crisis, and risk, were eliminated from the selection. Articles not sufficiently describing CFEs from the wider spectrum of content were also excluded. To concentrate on CFEs particularly related to physical environments and children experiences, preliminary reading was carried out and five more articles were extracted. Finally, 20 articles on CFEs focusing on the concept of sustainability were reviewed. Five additional articles were reviewed as supporting material to investigate the overall status of studies in CFEs. Contextual analysis of the final 20 articles was carried out to extract the child-friendliness factors that focused on children's experiences of the physical world (shown in Table 1). Additionally, two books that explore the relationship between child development and sustainable environments were referred to as supporting material.

\subsection{Evaluation Framework}

To conduct an impartial analysis of each article, a contextual analysing framework (shown in Table 1) was developed for the first stage of the critical review. This analysis framework aimed to extract principal factors from each article. The categories were mostly in two divisions: the physical environment setting and child-oriented aspect. These two categories were divided into subcategories: physical environment, including dimensions, features, and experience; and child-oriented aspect, including experience and development. The selected articles were analysed using this framework (as shown in Table 1). Subsequently, the critical factors of CFEs centred on children's experience of the physical environment were collected. This analysis framework allowed for an exhaustive analysis of each article. After the contextual analysis of each article was completed, an evaluation framework of CFEs was developed, consisting of four principal categories: sociality, wellness, development, and independence of children. These categories were derived from the factors discussed in the selected CFE papers and included in the evaluation framework. These factors were further categorised according to four critical experiential views of children (see Table 2). Each subcategory refers to the emotional, physical, and intellectual development context of children.

The evaluation framework for CFEs enabled a critical review of selected papers. A Harvey Ball was used to analyse the CFE value of each paper based on children's experiential categories indicated in the evaluation framework. In this way, the current status of CFE literature focusing on the children's experiences of the physical world was reviewed and evaluated. 
Table 2. An evaluation framework of child-friendly environments (CFEs), focusing on children's experiential perspectives.

\begin{tabular}{|c|c|c|}
\hline Category & Experiences & Clarification \\
\hline \multirow{4}{*}{ Sociality } & Sense of belonging & $\begin{array}{c}\text { Children feel like part of their environment through participating and } \\
\text { shaping their own places. }\end{array}$ \\
\hline & $\begin{array}{l}\text { Community } \\
\text { participation }\end{array}$ & $\begin{array}{l}\text { Engagement with social activities and the community can motivate children } \\
\text { to defend their rights and become responsible for their environment. }\end{array}$ \\
\hline & Social services & $\begin{array}{c}\text { Providing appropriate welfare and environmental management to keep the } \\
\text { environment sustainable. }\end{array}$ \\
\hline & Community facility & $\begin{array}{l}\text { Serving and supporting the diverse activity potential and } \\
\text { children's development. }\end{array}$ \\
\hline \multirow{4}{*}{ Wellness } & Happiness & Children feel satisfied with the environment that they are living in. \\
\hline & Health & $\begin{array}{c}\text { Providing a secure and hygienic environment to promote the physical and } \\
\text { emotional health of children. }\end{array}$ \\
\hline & Safety & $\begin{array}{l}\text { Providing a safe and secure environment to enhance the activity and } \\
\text { mobility of children. }\end{array}$ \\
\hline & Contact with nature & $\begin{array}{c}\text { Increasing the level of bodily experiences of children and wider exploratory } \\
\text { play to promote wellbeing. }\end{array}$ \\
\hline \multirow{4}{*}{ Development } & Feeling respected & $\begin{array}{l}\text { Children gain self-esteem through diverse opportunities in } \\
\text { their environment. }\end{array}$ \\
\hline & Exploratory play & $\begin{array}{l}\text { Encouraging children to gain a sense of place through sensory-rich } \\
\text { exploratory experiences in outdoor and indoor areas. }\end{array}$ \\
\hline & Creative activities & Empowering a greater creativity potential and wider social-scenario range. \\
\hline & Learning programs & $\begin{array}{l}\text { Providing an appropriate community program or workshop to allow } \\
\text { children to learn together in a social group. }\end{array}$ \\
\hline \multirow{4}{*}{ Independence } & Sense of self & $\begin{array}{l}\text { Children feel valued and gain a positive sense of self through their } \\
\text { experience of their environment. }\end{array}$ \\
\hline & Independent mobility & Allowing freedom of mobility and activity to children. \\
\hline & Affordances & $\begin{array}{l}\text { Providing clear perception of the physical environment to offer the } \\
\text { potential for diverse activity options. }\end{array}$ \\
\hline & Self-determination & $\begin{array}{l}\text { Children become capable of independent action, making choices, and } \\
\text { controlling their lives by making their own places. }\end{array}$ \\
\hline
\end{tabular}

\section{Critical Review of CFE Studies}

Of the 20 articles selected, 12 articles substantially focused on sustainability and the wellbeing of children, four articles focused on the healthy development of children in relation to the physical environment, and four articles focused on social infrastructure and management. Only seven articles considered diverse physical elements, such as playgrounds, roads, open spaces, and green spaces, and only five articles discussed multiple child-oriented activities in relation to the physical world. Many studies only included one or two specific elements, such as outdoor play, mobility, and affordance. While these elements are essential to CFEs, CFEs should pursue diversity in the physical environment to promote diverse experiences for children. This critical review presents an evaluation framework that considers the wider experiential perspective of children. All selected articles were evaluated according to this framework to enable an in-depth analysis of current studies of CFEs focusing on children's experiences of the physical environment.

\subsection{Sociality}

Sociality in CFEs considers children as stakeholders of society. Children have the right to take part in forming their own world. Accordingly, their experiences in the social environment are critical, including the following four critical experiential perspectives: 
- sense of belonging,

- community participation,

- social services,

- community facilities.

This is an important theme in CFE studies, encompassing 'sense of belonging', 'community participation', 'social services', and 'community facilities'. Putri et al. (p. 1, [5]) stated "city as community settlement with various ages must fulfil the right of every single person in the community, including children", based on Joga et al. [24]. This indicates that the world has begun to recognise the vital role of children in society. Putri [5] explored neighbourhood characteristics and social infrastructure relevant to children's rights through social activity and participation. This study investigated the social capacity for providing CFEs through a case study of Surakarta. It concluded that for the provision of CFEs, community capacity through the stages from implementation to maintenance should be powerful. Malone [17] and Nordström [18] focused on the authentic value of children's participation and children as the designers of urban development. These studies developed lists of child-friendliness indicators using children's iconic drawings and comments. These studies focused on children's agency in relation to the right of children to grow up with happy and healthy lifestyles including rich environmental experiences [17].

Corsi [9] Bridgman [10] and Bartholomaeus et al. [22] focused on the enhancement of interaction between society and children by implementing supportive community facilities or educational programs and activities. To fulfil the needs of children, they argued that the emotional, social, cultural, spiritual, and physical wellbeing of children must be considered [10]. Providing CFEs is not a simple matter that can be easily conducted using one or two focused areas. Sociality is crucial in CFE studies, allowing children to participate as active citizens who feel a sense of belonging within their neighbourhood context. The importance of sociality has been recognised repeatedly in many studies of CFEs. However, there is a lack of understanding of the perspective of children and their experiences of the physical environment. For example, we are aware that 'a sense of belonging' is important for children in CFEs. However, how and when children feel 'a sense of belonging' is the key aspect that this research intends to emphasise. This is because children relate to the environment differently from adults: their relationship is more sense-oriented [25]. Children use and conceive their environment through direct construction and manipulation [26], which means they only learn to experience via 'by doing', including active investigation, exploratory play, and discovery.

\subsection{Wellness}

Wellness in CFEs refers to the wellbeing of children in terms of emotional, physical, and social status. The positive experiences of children directly affect their development; therefore, the following four critical experiential perspectives are included:

- happiness,

- health,

- safety,

- contact with nature.

Many researchers have identified the concept of 'wellbeing' as a key issue in CFE studies [19]. However, few studies have defined wellbeing in domain knowledge. Wellbeing refers to the 'state of feeling healthy and happy' [27], which limits the context within the emotional wellness of children. This research suggests that the indicators that clearly categorise the term 'wellness' in CFEs are: happiness, health, safety, and contact with nature. Adams et al. [2] explored the child participatory perspective through an interview and found that children consider nature to be crucial in the creation of CFEs. Safe, natural spaces provide a great valuable to explore place-related happiness and subjective wellbeing. Wilks [7] focused on 'being safe' and 'feeling safe' as the main elements of CFEs. It argued 
that because "sense of safety influences children's behaviour" (p. 36, [7]), the geographical setting of the physical world must allow children to freely move around safely.

Provision of safety is one of children's basic rights. More importantly, the physical and mental health of children, which directly affects their bodies and emotions, should be fundamental to all CFE studies. Woolcook et al. [13] showed there has been a decline in the physical and mental wellbeing of Western children mainly because of the hybridised landscape created through gentrification. This study suggested that the development of policy is necessary to offer the particular and varied experiences that are beneficial to children [13]. The physical activity of children directly influences their physical health. Physical activity refers to very basic activities, such as walking and biking, which have been described as incidental physical activities. The American Academy of Pediatrics' Committee on Environmental Health [8] argued that these incidental physical activities play an important role in the energy balance of children. The neighbouring physical environment also is indicated as the principal influential factor in CFEs. Overall, in this research, the wellness of children is recognised as a fundamental factor that CFEs must consider.

The absence of consideration of children's experiential perspectives is examined in this research. When do children feel happy? How do they determine themselves to be happy? The environment influences children's emotional, social, intellectual, and physical development [12]. Amerijckx and Humblet [19] argued that people link wellbeing with values as a symbol of happiness. Similarly, wellness and happiness are inseparable from CFEs. Up until now, studies have not explored the catalyst for the emotional experiences of children related to their experiences of the physical environment.

\subsection{Development}

Development is about the progress of children through life. They grow and improve by processing their experiencing of surrounding environments. Development includes the following four critical experiential perspectives of children:

- feeling respected,

- exploratory play,

- creative activities,

- learning programs.

The development of children is inseparable from CFEs. At the beginning of the twenty-first century, it was a focus for scholars of CFEs. Development is what childhood is about. Children need to feel valued and protected for healthy development [12]. Healthy development refers to balanced emotional, physical, and intellectual development. However, development in CFE studies has been limited by adult criteria, which vigorously focused on the intellectual and physical development of children from an adult perspective. Villanueva et al. [14] initiated the study by asking "can the neighbourhood built environment make a difference in children's development?" (p. 1, [14]). This study focused on the relevance of neighbourhood environments for child development. Neighbourhood contexts including access to local amenities, traffic exposure, housing density, and access to nature are significant features that affect children's time outside of home and school [14]. Outer suburban areas with detached housing, sufficient green spaces, and low-density development have been identified as the most preferable location for families with children [14]. Children experience the environment through exploration [12], and this greatly affects their development.

The provision of diverse exploratory play, activities with creative potential, and learning programs is essential in CFEs, which are intended to be affected by the setting of the physical environment, including local amenities, green spaces, playgrounds, and community facilities. Similarly, Islam et al. [20] and Wridt [21] emphasised the importance of neighbourhood environments for child development. The role of the built environment is to promote physical activity. This is closely related to the obesity of children [21]. The physical characteristics of the environment greatly affect the amount of time children spend outdoors. They consequently affect the level of physical activity of children 
and are crucial to their healthy development [20]. Community programs and learning opportunities are significant factors in the intellectual development of children. Since children are sense-oriented while experiencing the environment, providing diverse opportunities for exploration and creativity is essential for CFEs [8]. Community play programs are a good example: they allow children to participate in their social environment through an intellectual or physical development program.

The ultimate aim of CFEs is sustainability - that is, providing a sustainable environment and enabling sustainable child development. Sustainable urban development significantly affects children's everyday lives; however, the characteristics of urban living have dramatically changed, affecting child development and their life progression. Christensen et al. [1], therefore, emphasise the importance of achieving sustainable environments for children. Chang and Finkbeiner [4] explored SD from a child's perspective, arguing that children are ignored as a relevant stakeholder group in the context of SD in our society. SD is defined as "development that meets the needs of the present without compromising the ability of future generations to meet their own needs" (p. 11, [28]). This definition highlights the equal rights of every human being, including adults and children [4]. Children as stakeholders in our society must be granted equal opportunities to develop in freedom and in well-balanced environments. Therefore, environmental equality for all members of society can be achieved through the creation of CFEs based on SD principles of valuing children's balanced development.

\subsection{Independence}

Independence in CFEs focuses on the value of individuality for children in an environment that offers secure and safe conditions without supervision from adults. Independence includes the following four critical experiential perspectives of children:

- $\quad$ sense of self,

- independent mobility,

- affordances,

- $\quad$ self-determination.

Children are not living in a part of the adult world: they are living in the world as individual human beings with their own rights. Many researchers in the field of CFEs recognise the individual value of children and emphasise the importance of children's rights in society. However, what specific consideration has this world provided to children for them to form their own places? How do physical environments meet children's needs? Most urban designs assume that children will just fit in [12]. Naturally, children need care and protection from adults, but this does not mean that they need control and the anxiety of adults, which limit their possibilities and self-esteem. This research suggests a final category named 'independence' as being crucial in CFEs. This category includes the following subcategories: sense of self, independent mobility, affordances, and self-determination. Within this category, the balanced physical, intellectual, and emotional development of children are all valued.

Children find affordances for play and form their own places in environments [15]. Jansson et al. [15] focused on the interrelation between children's independent mobility and affordances. Affordance is defined by Jansson et al. [15] as a perceived environmental quality for use and activities, which importantly affects the physical activities of children related to development. Provision of a safe, adequate physical environment allowing freedom of movement and activities for children is crucial. For example, a shrinking of open spaces and a high level of traffic would decrease the level of independent mobility of children. Interestingly, Jansson et al. [15] showed that a high level of community activation of adults resulted from an environment that provided a high level of independent mobility and physical activity to children. Similarly, Kyttä [11] and Carroll et al. [6] argued that children's level of independent mobility influences their physical, social, cognitive, and emotional development. Motivating children to be independently mobile is critical for their healthy development. To be more effective, the high level of actualised affordances should be presented in the physical environment in order to motivate children to be independently mobile. From the evaluation of papers, it is clear 
that many have focused on the physical formation of CFEs relevant to children's independence. The emotional experience of children has been somewhat ignored in many research studies. Importantly, children need to feel valued, protected, and safe for their healthy development [12]. Children's environmental consciousness and their emotional experience of the physical environment must be further explored in future studies.

Through the critical review of the 20 selected articles, the development of CFEs has been recognised as being not a single aspect of a single dimension. Rather, it is complicated, involving multiple factors, such as physical, social, emotional, and intellectual factors. The relationships between these factors need to be explored in depth. Many researchers have discussed various lists of influential factors in CFEs. However, these influential factors required sets of classification and clear clarification of each category.

Therefore, this research developed an evaluation framework for CFEs, consisting of four principal categories: sociality, wellness, development, and independence of children. Through the application of this framework, each selected paper in the field of CFEs was evaluated from a balanced and equalised perspective for critical review. The results are as shown in Table 3. The use of Harvey Balls allowed for a qualitative evaluation of each article based on the categories set out in the evaluation framework (shown in Table 2). This stage of the critical review was significant, showing the current status of studies of CFEs and which sub-areas current CFE studies have explored. From our results, we were able to determine which areas of CFEs require more in-depth exploration in the future in order to provide adequate CFEs for children.

Sociality (specifically community participation and social services) was found to be the most studied area. Many studies have argued that the improvement of children's participation levels in communities will directly influence the creation of adequate CFEs for children. Wellness was the second most popular subject, in which the health and safety of children was the most important concern. Some studies have explored being with nature in relation to the wellbeing of children. However, the level of depth of exploration was not adequate. Independence, including independent mobility and affordance, was found to be a significant factor for CFEs in direct relation to the physical world.

Lastly, development, which is critically relevant to the emotional and intellectual life progression of children, has not been adequately explored in many studies. While many studies have pointed out its significance, no adequate in-depth indicator or framework has been developed. The development category should be further explored in future studies of CFEs because this is critical for the diversity of physical environments. As argued earlier, more diverse physical environments should provide children with various opportunities for play and activity, which will eventually positively affect the development of children. Overall, in future studies of CFEs, more in-depth exploration of children's emotional perspectives is required. The spatial cognition and environmental experiences of children are sense oriented, and this should be respected in providing CFEs for children. 
Table 3. Qualitative critical analysis of 20 selected articles based on the critical evaluation framework (shown in Table 2).

\begin{tabular}{|c|c|c|c|c|c|c|c|c|c|c|c|c|c|c|c|c|c|c|c|c|c|c|}
\hline Category & Experience & [3] & [15] & [11] & [5] & [19] & [14] & [20] & [6] & [17] & [18] & [21] & [2] & [7] & [9] & [13] & [10] & [22] & {$[8]$} & [23] & [4] & Total \\
\hline \multirow{4}{*}{ Sociality } & Sense of belonging & ( & - & 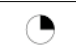 & 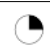 & $\boldsymbol{C}$ & O & O & ( & $\rightarrow$ & ( ) & $\rightarrow$ & ( & 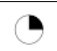 & $\mathrm{O}$ & $\mathrm{O}$ & $\mathrm{O}$ & 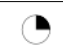 & O & O & 0 & (1) \\
\hline & $\begin{array}{l}\text { Community } \\
\text { participation }\end{array}$ & ( & 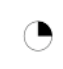 & - & 0 & - & $\rightarrow$ & - & D & 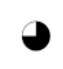 & $\ominus$ & ( & ( & D & - & $\ominus$ & 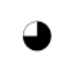 & $\bullet$ & $\rightarrow$ & $\rightarrow$ & D & ( \\
\hline & Social service & $\boldsymbol{\ominus}$ & - & b & - & 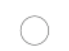 & 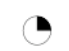 & O & D & 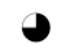 & $\ominus$ & 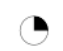 & 0 & ( & () & $\ominus$ & $\rightarrow$ & $\boldsymbol{\theta}$ & - & $\bullet$ & $\checkmark$ & 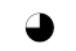 \\
\hline & Community facility & - & - & D & 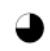 & O & 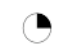 & $\rightarrow$ & ( & ( & 0 & $\rightarrow$ & $\rightarrow$ & 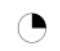 & ( & ( & 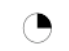 & 0 & ( & ( & 0 & ( \\
\hline \multirow{4}{*}{ Wellness } & Happiness & $\boldsymbol{C}$ & O & O & O & 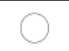 & O & O & - & O & O & O & - & 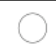 & J & O & 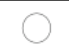 & 0 & O & O & & 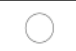 \\
\hline & Health & 0 & $\rightarrow$ & 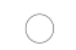 & 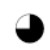 & 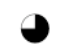 & ( & $\rightarrow$ & 0 & O & $\rightarrow$ & () & ( & ( & 0 & ( & ( & D & - & $\rightarrow$ & P & () \\
\hline & Safety & - & 0 & 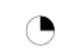 & ( & & $\ominus$ & ( & 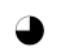 & $\rightarrow$ & $\ominus$ & $\rightarrow$ & ( & D & ( & 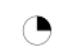 & $\ominus$ & 0 & 0 & O & D & $\bullet$ \\
\hline & Contact with nature & - & 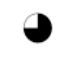 & - & O & & $\rightarrow$ & - & 0 & 0 & 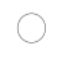 & $\rightarrow$ & $\boldsymbol{\ominus}$ & $\Omega$ & 0 & O & O & 0 & O & $\mathbf{D}$ & D & - \\
\hline \multirow{4}{*}{ Development } & Feeling respected & O & 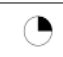 & 0 & O & O & O & O & O & $\rightarrow$ & 0 & 0 & $\rightarrow$ & O & O & O & O & 0 & O & 0 & & O \\
\hline & Exploratory play & - & O & $\rightarrow$ & 0 & 0 & D & D & $\ominus$ & $\rightarrow$ & - & $\boldsymbol{\theta}$ & 0 & 0 & 0 & 0 & O & 0 & - & $\rightarrow$ & 0 & - \\
\hline & Creative activities & - & - & - & 0 & 0 & - & 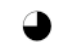 & $\ominus$ & O & 0 & ( & 0 & 0 & 0 & O & 0 & $U$ & - & $\rightarrow$ & 0 & - \\
\hline & Learning programs & O & O & O & O & ( & 0 & O & 0 & O & O & 0 & ( & O & O & ( & D & O & ( & $\bullet$ & $\ominus$ & D \\
\hline \multirow{4}{*}{ Independence } & Sense of self & O & ( & $\rightarrow$ & 0 & O & O & O & O & 0 & $U$ & O & 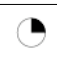 & 0 & $U$ & O & O & O & O & O & 0 & 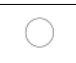 \\
\hline & Independent mobility & - & ( & & - & 0 & $\rightarrow$ & O & ( & - & $\rightarrow$ & - & 0 & 0 & $\rightarrow$ & $\rightarrow$ & O & $\rightarrow$ & $\rightarrow$ & O & 0 & D \\
\hline & Affordance & $\boldsymbol{-}$ & ( & 0 & - & 0 & O & O & 0 & ( & $\rightarrow$ & $\rightarrow$ & 0 & 0 & 0 & 0 & O & O & 0 & 0 & 0 & 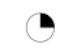 \\
\hline & Self-determination & - & 0 & 0 & 0 & O & 0 & O & 0 & - & 0 & 0 & 0 & 0 & 0 & 0 & O & 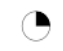 & 0 & O & 0 & O \\
\hline
\end{tabular}




\section{Conclusions and Discussion}

Many researchers have defined CFEs as sustainable environments that contribute to multiple values in the world for all users, specifically children. In other words, the creation of CFEs will potentially provide sustainable environmental equality for all users without substantial effects from urban and social changes. United Nations Children's Fund (UNICEF)'s child-friendly city initiative is committed to the rights of children in regard to their living quality [24]. The practical development of CFEs is a critical assignment, socially and globally. However, there has been a lack of evaluation of CFEs focusing on the experiences of children, in recognising children as central users of the physical environment. Many studies have explored CFEs using the criteria of adults [12]. These criteria have focused on major factors in the social context. As argued in this research, to develop adequate CFEs for children, more in-depth studies on children's experiential perspectives must be conducted. The current environment undermines children's natural sense of reverent wonder. For example, some adults may believe that brightly coloured teddy bear wallpaper would be perfect for children, but those features do not foster children's imagination and intuitive sense of truth [12].

Children grow, progress, and develop through their surrounding environment. Their personal identity is formed within their environment. Therefore, the development of CFEs must consider a variety of factors, including sustainability, children's healthy development, and their wellbeing. This research suggests that there are four crucial factors specifically relevant to the experiential perspectives of children:

- sociality - sense of belonging, community participation, social services, and community facilities;

- $\quad$ wellness-happiness, health, safety, and contact with nature;

- development-feeling respected, exploratory play, creative activities, and learning programs;

- independence—-sense of self, independent mobility, affordances, and self-determination.

Each factor includes subcategories that relate to the emotional, physical, and intellectual experiential aspect of children (shown in Table 2). This evaluation framework suggests that future research on CFEs should consider the diverse experiential perspectives of children.

The population of the world is ageing, and this must be a key concern for urban scholarship. Children play an important role in society. They must be seen as central users of the world and given adequate environments in which to live, play, and develop with respect. This research analysed articles on CFEs, focusing on children's experiential perspectives on the physical environment. We argued that the balanced emotional, physical, and intellectual development of children should be promoted through the development of CFEs because children's spatial cognition is different from that of adults. The knowledge gained by this critical research can be a source of inspiration for future studies of CFEs. In addition, because the significance of providing adequate CFEs is indicated by this research, we hope more practical studies of CFEs that incorporate a more in-depth understanding of children will be conducted in the future.

Author Contributions: M.J.N.H. composed this study, designed the evaluation framework and completed qualitative critical analysis. M.J.K. provided her supervision of all the research process and substantially contributed to the methodological design of this research.

Funding: This work was supported by the National Research Foundation of Korea (NRF) grant funded by the Korean government (NRF-2016R1A2B4007752).

Conflicts of Interest: The authors declare no conflict of interest.

\section{References}

1. Christensen, P.; Hadfield-Hill, S.; Horton, J.; Kraftl, P. Children Living in Sustainable Built Environments: New Urbanisms, New Citizens; Routledge: Abingdon, UK, 2018.

2. Adams, S.; Savahl, S.; Florence, M.; Jackson, K. Considering the Natural Environment in the Creation of Child-Friendly Cities: Implications for Children's Subjective Well-Being. Child Ind. Res. 2018, 1-23. [CrossRef] 
3. Woolcock, G.; Steele, W. Child-Friendly Community Indicators-A Literature Review. Urban Research Program, Griffith University and NSW Commission for Children and Young People, 2008. Available online: https://childfriendlycities.org/wp-content/uploads/2017/11/Child-friendlyCommunity-Indicators-a-Literature-Review_2008.pdf (accessed on 23 April 2018).

4. Chang, Y.-J.; Finkbeiner, M. Evaluating Sustainable Development from a Child's Perspective-A Proposal of Sustainable Child Development Index (SCDI). Procedia CIRP 2016, 40, 475-480. [CrossRef]

5. Putri, R.A.; Astuti, W.; Rahayu, M.J. Community capacity in providing neighborhood unit-scale social infrastructure in supporting Surakarta child friendly. Procedia-Soc. Behav. Sci. 2016, 227, 536-544. [CrossRef]

6. Carroll, P.; Witten, K.; Kearns, R.; Donovan, P. Kids in the City: Children's use and experiences of urban neighbourhoods in Auckland, New Zealand. J. Urban Des. 2015, 20, 417-436. [CrossRef]

7. Wilks, J. Child-friendly cities: A place for active citizenship in geographical and environmental education. Int. Res. Geogr. Environ. Educ. 2010, 19, 25-38. [CrossRef]

8. Committee on Environmental Health. The built environment: Designing communities to promote physical activity in children. Pediatrics 2009, 123, 1591-1598. [CrossRef] [PubMed]

9. Corsi, M. The child friendly cities initiative in Italy. Environ. Urban. 2002, 14, 169-179. [CrossRef]

10. Bridgman, R. Criteria for best practices in building child-friendly cities: Involving young people in urban planning and design. Can. J. Urban Res. 2004, 13, 337-346.

11. Kyttä, M. The extent of children's independent mobility and the number of actualized affordances as criteria for child-friendly environments. J. Environ. Psychol. 2004, 24, 179-198. [CrossRef]

12. Day, C.; Midbjer, A. Environment and Children; Routledge: Abingdon, UK, 2007.

13. Woolcock, G.; Gleeson, B.; Randolph, B. Urban research and child-friendly cities: A new Australian outline. Child. Geogr. 2010, 8, 177-192. [CrossRef]

14. Villanueva, K.; Badland, H.; Kvalsvig, A.; O'Connor, M.; Christian, H.; Woolcock, G.; Giles-Corti, B.; Goldfeld, S. Can the neighborhood built environment make a difference in children's development? Building the research agenda to create evidence for place-based children's policy. Acad. Pediatr. 2016, 16, 10-19. [CrossRef] [PubMed]

15. Jansson, M.; Sundevall, E.; Wales, M. The role of green spaces and their management in a child-friendly urban village. Urban For. Urban Green. 2016, 18, 228-236. [CrossRef]

16. Liddle, B.; Moavenzadeh, F. Cities: Challenges and opportunities for sustainability. In Future Cities: Dynamic and Sustainability; Moavenzadeh, F., Hanaki, K., Baccini, P., Eds.; Kluwer Academic Publishers: London, UK, 2002; pp. 1-15.

17. Malone, K. "The future lies in our hands": Children as researchers and environmental change agents in designing a child-friendly neighbourhood. Local Environ. 2013, 18, 372-395. [CrossRef]

18. Nordström, M. Children's views on child-friendly environments in different geographical, cultural and social neighbourhoods. Urban Stud. 2010, 47, 514-528. [CrossRef]

19. Amerijckx, G.; Humblet, P.C. Child Well-Being: What Does It Mean? Child. Soc. 2014, 28, 404-415. [CrossRef]

20. Islam, M.Z.; Moore, R.; Cosco, N. Child-friendly, active, healthy neighborhoods: Physical characteristics and children's time outdoors. Environ. Behav. 2016, 48, 711-736. [CrossRef]

21. Wridt, P. A qualitative GIS approach to mapping urban neighborhoods with children to promote physical activity and child-friendly community planning. Environ. Plan. Plan. Des. 2010, 37, 129-147. [CrossRef]

22. Bartholomaeus, C.; Gregoric, C.; Krieg, S. Young children as active citizens in local government: Possibilities and challenges from an Australian perspective. Int. J. Early Child. 2016, 48, 79-93. [CrossRef]

23. Choi, J. Family friendly community environment for child and family care. Rev. Architect. Build. Sci. 2013, 57, $18-24$.

24. Joga, N. Gerakan Kota Hijau; Gramedia Pustaka Utama: Jarkarta, Indonenisa, 2013.

25. Björklid, P.; Nordström, M. Child-Friendly Cities-Sustainable Cities. Available online: https:/ / bernardvanleer.org/app/uploads/2017/10/ECM118_10_Child-friendly-cities-sustainablecities_Pia-Bjorklid.pdf (accessed on 29 March 2018).

26. Jansson, M. Children's perspectives on playground use as basis for children's participation in local play space management. Local Environ. 2015, 20, 165-179. [CrossRef] 
27. Cambridge Dictionary. Available online: https://www.google.com/search?q=Dictionary\#dobs=well-being (accessed on 13 August 2018).

28. Redclift, M. The environmental consequences of Latin America's agricultural development: Some thoughts on the Brundtland Commission report. World Dev. 1989, 17, 365-377. [CrossRef] 